\title{
VIT-CMJ2: Endophyte of Agaricus bisporus in Production of Bioactive Compounds
}

\author{
Chandan Kumar Gautam, Mukund Madhav, Astha Sinha, William Jabez Osborne * \\ Department of Biomolecules Lab, School of Bio Sciences and Technology, VIT University, Vellore, India \\ *Corresponding author: William Jabez Osborne, Department of Biomolecules Lab, School of Bio Sciences and Technology, VIT University, Vellore, India. \\ Tel: +91-9894204309, Fax: +91-4162243092, E-mail: jabezosborne@vit.ac.in
}

Received: July 08, 2015; Revised: December 05, 2015; Accepted: February 15, 2016

\begin{abstract}
Background: Agaricus bisporus is an edible basidiomycete fungus. Both the body and the mycelium contain compounds comprising a wide range of antimicrobial molecules, contributing in improvement of immunity and tumor-retardation. Objectives: The presence of endophytes capable of producing bioactive compounds was investigated in Agaricus bisporus. Materials and Methods: Endophytes from Agaricus bisporus was isolated on LB agar. The obtained isolates were characterized morphologically and biochemically. Further 16S rRNA sequencing was implemented for molecular analysis of isolates. The isolate was mass produced and the bioactive compounds were extracted using ethyl acetate, chloroform and hexane. Agar well diffusion method was carried out to seek the potential of any antimicrobial activity of the crude bioactive compounds against known pathogens. GC-MS and FT-IR analysis were performed for the identification of bioactive compounds.

Results: VIT-CMJ2 was identified as Enterobacter sp. as revealed by 16S rRNA sequencing. Chloroform extract of VIT-CMJ2 showed a maximum zone of inhibition of $19 \mathrm{~mm}$ against Salmonella typhi followed by hexane and ethyl acetate extracts. The GC-MS analysis revealed the presence of several bioactive compounds having effective antimicrobial activity like butyl ester, Behenicalcohol, S, S-dioxide derivatives and some others which were later confirmed by FT-IR spectral stretches.

Conclusions: The present study shows the insight on the way endophytes interact with Agaricus bisporus; thereby improving the nutritional profile.

Keywords: Antibacterial activity; Behenic alcohol; Button mushroom; Butyl ester; Endophytes; FT-IR; GC-MS; 16S rRNA
\end{abstract}

\section{Background}

Mushrooms are used as a common edible food and as a traditional Asian medicinal system across the globe (1). About 2000 varieties of edible mushrooms have been reported amongst which less than 100 varieties are cultivated, the rest are obtained from the wild varieties (2). Among the cultivated varieties of mushroom, the button mushroom (Agaricus bisporus) dominates the global market (3). Mushrooms are rich in protein, minerals, vitamin $\mathrm{D}$, unsaturated fatty acids, immunologically active polysaccharides and sterols (4-6). Further, low fat and presence of dietary fibers make it a good choice for calorie conscious people (3). Like plants, mushroom is also associated with some (mainly Mushroom Growth Promoting Bacteria) microbes known as endophytes, which help in its growth.

Endophytes are mainly bacteria or fungi living inside plants, animals or other living system. They generally show endosymbiosis with the host, resulting in mutual benefit. Fungal endophytes in plant help the roots in nutrients absorption, preventing infection and supports in growth $(7,9)$. Twenty three strains of mushroom growth promoting bacteria have been identified from 14 different mushroom farms $(7,8)$.

The most widely consumed mushroom; Agaricus have also been investigated for its association with some beneficial bacteria. Agaricus blazei have been found to be associated with actinobacteria that help to reduce the harvest time and at the same time increases the total polysaccharide-protein complex content (9). So far, association studies were used to analyze interaction between the microbes and mushroom substrate or mycelium. Only a meagre work has been reported on the endophytes isolated from edible mushroom, its identification and metabolite profiling.

The bioactive metabolites are either produced by mushroom itself or by some endophytes. Recent studies focuses on identification of numerous bioactive compounds with immuno-active and anticancer properties, optimization of substrate, strain improvement, 
improvement of culture conditions and microbial ecology of the mushroom (10).

\section{Objectives}

The microbial association of Agaricus bisporus was investigated. The metabolites of the endophytic microbes from this mushroom were analyzed to identify the bioactive molecules and were tested against known pathogens for the antibacterial activity. The metabolites of these endophytes may be responsible for some of the bioactive compounds in button mushroom.

\section{Materials and Methods}

\subsection{Sample Collection and Chemicals}

Fresh button mushrooms (Agaricus bisporus) were procured from a local vegetable market in Vellore, Tamil Nadu, India and were processed immediately. Luria Bertani (LB) agar media and broth were purchased from the HiMedia Laboratories, Mumbai.

\subsection{Isolation of Endophytic Bacteria}

To isolate endophytic bacteria, mushroom were surface sterilized with three washes of $\mathrm{dH}_{2} \mathrm{O}$ followed by $4 \% \mathrm{NaOCl}$ solution and $70 \%$ ethanol (11). Blocks of mushroom $\left(1 \mathrm{~cm}^{3}\right)$ were impregnated on LB agar plates and were incubated at $28 \pm 2^{\circ} \mathrm{C}$ for $24 \mathrm{~h}$. The endophytic isolates were selected based on colony morphology and were purified and maintained on LB agar slant. Biochemical and morphological characterization was performed based on Bergey's manual. One distinct isolate was selected and named as VIT-CMJ2 $(11,12)$.

\subsection{Endophytic Bacterial Culture Inoculum}

VIT-CMJ2 was cultured in LB and incubated at $28 \pm 2^{\circ} \mathrm{C}$ till the optical density reached $0.5\left(1.5 \times 10^{8}\right.$ cfu. $\left.\mathrm{mL}^{-1}\right)$. Inoculum $(2 \% \mathrm{v} / \mathrm{v})$ from this pre-grown culture was used to inoculate $350 \mathrm{~mL}$ of LB at $28 \pm 2^{\circ} \mathrm{C}$ for 5 days on a rotary shaker at $120 \mathrm{rpm}$ (13).

\subsection{Solvent Extraction}

The broth of VIT-CMJ2 culture was extracted using chloroform, n-hexane and ethyl acetate. The extracted metabolites were dried over anhydrous $\mathrm{Na}_{2} \mathrm{SO}_{4}$, dissolved in HPLC grade solvents and were further analytically analyzed using GC-MS and FT-IR (14).

\subsection{Antimicrobial Activity}

Antimicrobial activity of crude extracts of endo- phytic bacteria VIT-CMJ2 was assessed against known pathogens such as Salmonella typhi (MTCC No. 8587), Escherichia coli (MTCC No. 9721), Bacillus subtilis (MTCC No. 2547) and Staphylococcus aureus (MTCC No. 3160). Seed culture $(\mathrm{O} . \mathrm{D}=0.5)$ of all the bacterial pathogens were prepared and swabbed evenly onto Muller hinton agar plate; wells were prepared using cork borer and $100 \mu \mathrm{L}\left(10^{8} \mathrm{cfu} \mathrm{mL}^{-1}\right)$ of crude VIT-CMJ2 extracts were added at a concentration of $300 \mathrm{mg} . \mathrm{L}^{-1}$ to each well. The well containing only solvent was considered as negative control and Ciprofloxacin and Rifampin (100 mg.L-1) as positive control. The plates were incubated at $37^{\circ} \mathrm{C}$ and zone of inhibition were measured in $\mathrm{mm}$ after overnight incubation (15).

\subsection{GC-MS Analysis}

Gas chromatography coupled to mass spectrometer was used to identify the metabolites produced by the endophytic microbes $(16,17)$. For the detection of various metabolites obtained in the solvent extracts of effective isolate VIT-CMJ2, the samples were given for GC-MS analysis along with the controls i.e. (LB). GC-MS analysis was performed using Perkin Elmer GC model $(30 \mathrm{~m} \times 0.25 \mathrm{~mm} \times 0.25 \mu \mathrm{m})$ and Clarus 680 (Mass spectrometer Clarus $600 \mathrm{EI}$ ) apparatus with an injection volume of $1 \mu \mathrm{L}$, oven temperature was programmed from $60^{\circ} \mathrm{C}$ to $300^{\circ} \mathrm{C}$ for $2 \mathrm{~min}$ at the rate of $10^{\circ} \mathrm{C} / \mathrm{min}$ and isothermally held for $6 \mathrm{~min}$ until the analysis was completed.

\subsection{FT-IR Analysis}

FT-IR analysis was performed in order to investigate the different functional groups present in crude VIT-CMJ2 extract. FT-IR analysis was performed on Nicolet FT-IR (Avatar-330) in 400-4000 $\mathrm{cm}^{-1}$ with 16 scan speed (18).

\section{8. $16 S$ rRNA Sequencing}

The isolated bacteria VITCMJ-2 were sequenced using 16S rRNA technique using universal primers 27F (5'-AGAGTTTGATCCTGGCTCAG-3') and 1492R (5'-GGTTACCTTGTTACGACTT-3') The bacterial DNA was extracted from the cells and 16S rRNA sequence was determined using fluorescent dye terminator method with the help of the sequencing kit (ABI Prism Big dye terminator cycle sequencing ready reaction kit v.3.1). Products were run on an ABI13730XL capillary DNA sequencer (ABI Prism 310 genetic analyzer, Tokyo, Japan). The ClustalW software was used to compute the aligned sequences and an evolutionary 
distance matrix was created through determination of sequence homologies using BLASTn search (31).

\section{Results}

\subsection{Isolation and Identification of Effective} Endophytic Bacteria

Based on different cellular and morphological characteristics VIT-CMJ2 was selected and maintained on LB agar plates. Morphological and biochemical analysis revealed VIT-CMJ2 to be gram negative rod and positive for nitrate reduction, glucose, citrate, ornithine, arabinose, and sorbitol utilization and negative for urease, phenylalanine deamination, $\mathrm{H}_{2} \mathrm{~S}$ production and lysine, adonitol and lactose utilization test. 16S rRNA gene sequencing revealed VITCMJ2 to be a close neighbor of Enterobacter ludwigii (Figure 1). The sequence was further submitted in NCBI Genbank (accession number KJ437474).

\subsection{Antibacterial Activity}

The hexane, ethyl acetate and chloroform extract of the VIT-CMJ2 strain exhibited antibacterial activity against the tested pathogens. The maximum activity was displayed by the chloroform extract having a zone of inhibition of $19 \mathrm{~mm}$, followed by ethyl acetate (15 $\mathrm{mm})$ and hexane $(11 \mathrm{~mm})$ extracts. All the extracts showed maximum activity against Salmonella typhi and minimum activity against $E$. coli.

\subsection{GC-MS Analysis}

The bioactive compound present in chloroform, hexane and ethyl acetate extracts of VIT-CMJ2 was detected by GC-MS. The peaks obtained were compared with the database available and the analysis revealed the presence of the following major group of compounds (Figure 2A, B and C). GC-MS analysis revealed the presence of compounds like butyl ester, behenic alcohol, 1-amino cyclopentane hydroxamic acid and methylphenidate among the various secondary metabolites produced by VIT-CMJ2 effective in possessing antimicrobial activities.

\subsection{FT-IR Analysis}

The FTIR analysis of the ethyl acetate, chloroform and hexane extract of VIT-CMJ2 revealed the major peaks in IR range of $3446 \mathrm{~cm}^{-1}, 2935 \mathrm{~cm}^{-1}, 1641 \mathrm{~cm}^{-1}$, $1402 \mathrm{~cm}^{-1}, 1051 \mathrm{~cm}^{-1}$ and $1219 \mathrm{~cm}^{-1}$ corresponding to $\mathrm{O}-\mathrm{H}$ stretch, H-bonded stretch, $\mathrm{C}-\mathrm{H}$ stretch,-C $=\mathrm{C}$ stretch, C-C stretch (in-ring) of aromatic compounds, $\mathrm{C}-\mathrm{N}$ stretch of aliphatic amines respectively (Figure $3 \mathrm{~A}, \mathrm{~B}$ and $\mathrm{C}$ ).

\section{Discussion}

Mushrooms are valued throughout the world as both food and medicine for thousands of years and have been considered as a rich source for the production of effective bioactive metabolite and drugs since ancient times $(19,10)$. Endophytes are relatively

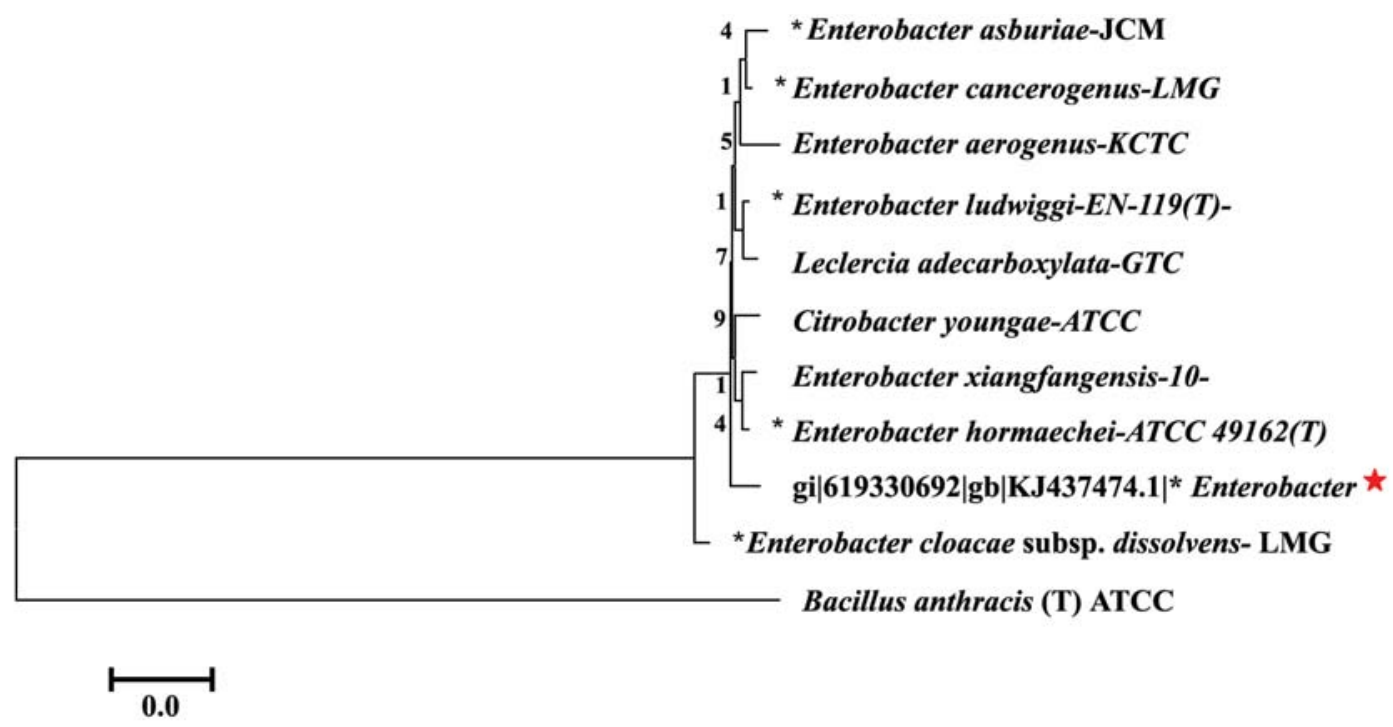

Figure 1. Phylogenetic tree of VIT CMJ 2(Creamy) colony based on the nucleotide sequences of 16S rRNA genes. * Represents a taxonomic group that includes species/subspecies that are not distinguishable by 16S rRNA gene sequence 

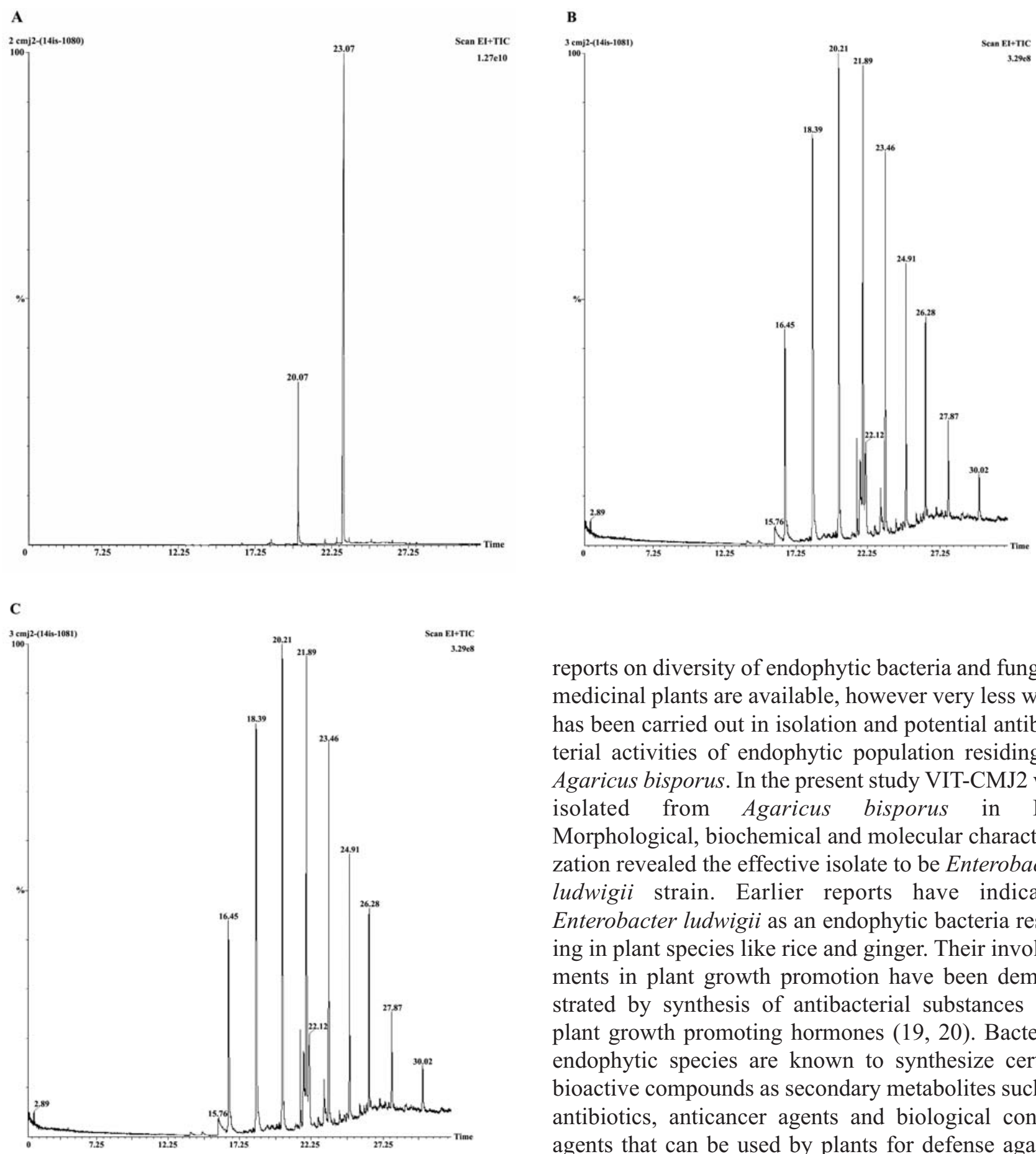

Figure 2. A: Chromatogram of Enterobacter ludwigii strain VITCMJ2 using hexane. B: Chromatogram of Enterobacter ludwigii strain VIT-CMJ2 using chloroform. C: Chromatogram of Enterobacter ludwigii strain VIT-CMJ2 using ethyl acetate

unstudied and can be of a great interest, especially in understanding their potential antibacterial activities and exploring their probabilities for the development of novel natural products. Countable numbers of

reports on diversity of endophytic bacteria and fungi in medicinal plants are available, however very less work has been carried out in isolation and potential antibacterial activities of endophytic population residing in Agaricus bisporus. In the present study VIT-CMJ2 was isolated from Agaricus bisporus in LB. Morphological, biochemical and molecular characterization revealed the effective isolate to be Enterobacter ludwigii strain. Earlier reports have indicated Enterobacter ludwigii as an endophytic bacteria residing in plant species like rice and ginger. Their involvements in plant growth promotion have been demonstrated by synthesis of antibacterial substances and plant growth promoting hormones $(19,20)$. Bacterial endophytic species are known to synthesize certain bioactive compounds as secondary metabolites such as antibiotics, anticancer agents and biological control agents that can be used by plants for defense against pathogens (21).

Secondary metabolites from effective isolate VITCMJ2 were extracted using hexane, chloroform and ethyl acetate as solvents and the obtained crude extract were assessed for its antimicrobial activity against known pathogens like Salmonella typhi (MTCC No. 8587), E. coli (MTCC No. 9721), Bacillus subtilis (MTCC No. 2547) and Staphylococcus aureus (MTCC No. 3160) by agar well diffusion method, where the zone of inhibition around the wells directly indicated 

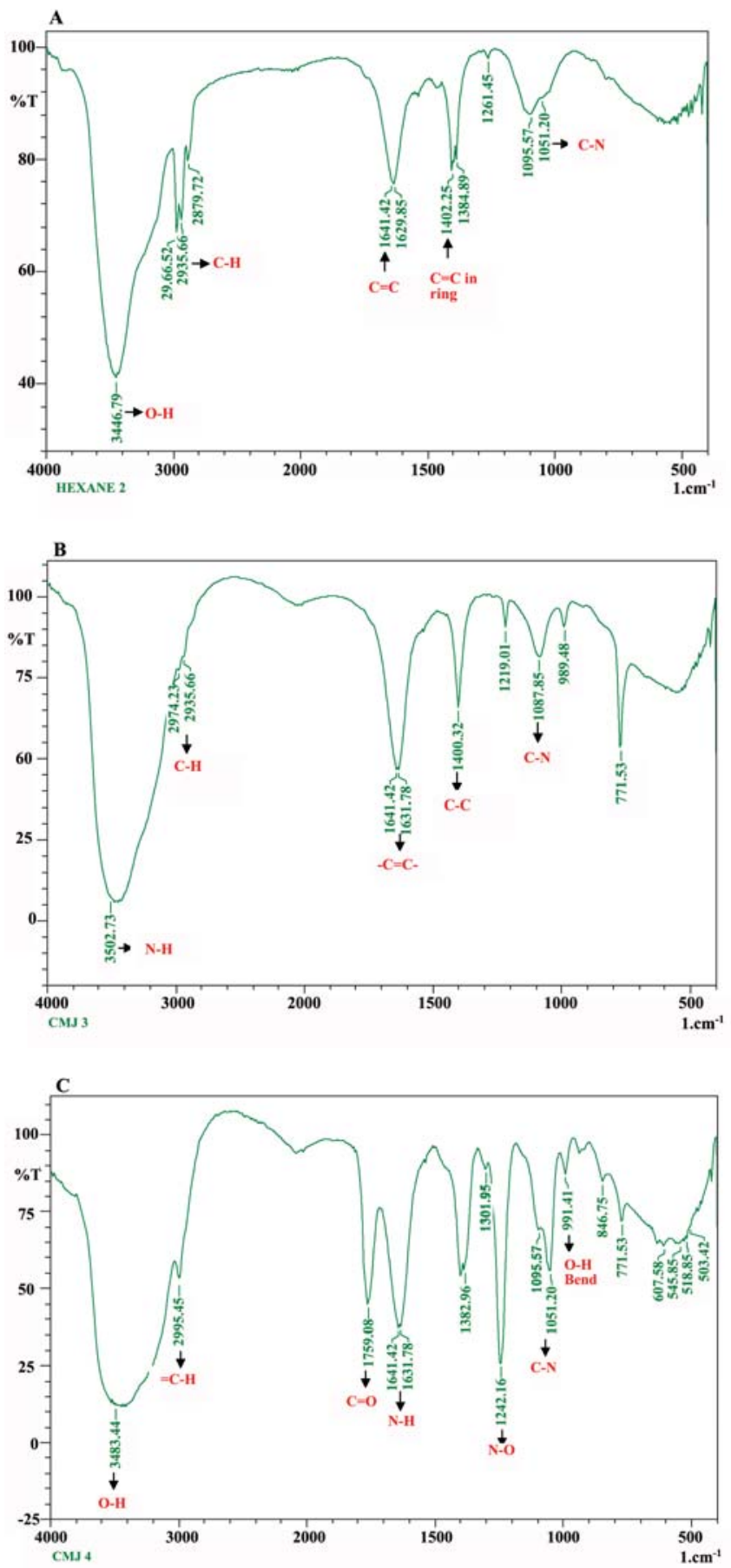

Figure 3. A: FT-IR spectra of VIT-CMJ2 using hexane. B: FT-IR spectra of VIT-CMJ2 using choloroform. C: FT-IR spectra of VITCMJ2 using ethyl acetate

the efficiency of the bioactive compound to act against the tested pathogens. The maximum activity was shown by the chloroform extract having the zone of inhibition (19 $\mathrm{mm})$ against Salmonella typhi (15). The extract of VIT-CMJ2 on the basis of spectral data by GC-MS analysis was found to be a mixture of many compounds.
We have identified that the bacterial endophytes VIT-CMJ2 from button mushroom produces several bioactive molecules both aliphatic and aromatic. GCMS analysis revealed the presence of compounds like butyl ester, behenic alcohol, 1-amino cyclopentane hydroxamic acid and methylphenidate effective in possessing antimicrobial activities. Recent reports have revealed the effectiveness of butyl alcohol to act as an antimicrobial agent against vast range of pathogens including E. coli DMF 7503, B. cereus DMF 2001, Listeria monocytogenes DMF 5776 and Saccharomyces cerevisiae DMF 1017 (20). Behenic alcohol, 1-aminocyclopentane hydroxamic acid, methylphenidate were reported to be effective against a wide range of microbial agents (21). GC-MS spectra also reveled the presence of compounds such as 1heptacosenol in the chloroform extract which has multiple potential activities to act as a antimicrobial, nematicidal, anticancer and antioxidant agent. The ethyl acetate extract reported mainly the presence of chloro derivatives of hydrocarbons. It also showed the presence of methylphenidate, a substituted phenethylamine and psycho stimulant drug used for the treatment of the attention deficit hyperactivity disorders. The functional groups of the hexane, ethyl acetate and chloroform extract of VIT-CMJ2 were also analyzed using Fourier Transform Infra Red spectroscopy (FTIR) and it revealed the presence of functional groups such as $\mathrm{C}-\mathrm{O}, \mathrm{C}=\mathrm{C}$ (aromatic), $\mathrm{C}=\mathrm{O}$ (amides), $\mathrm{O}-\mathrm{H}$ (acid), $\mathrm{C}-\mathrm{H}$ (alkyl) and $\mathrm{C}=\mathrm{O}$ (amide) in the extracts of VIT-CMJ2, in agreement with GC-MS $\mathrm{m} / \mathrm{z}$ ratio for the presence of same functional groups. Further this study proves that the endophytic bacterium residing in Agaricus bisporus is an endophyte that is capable of antibacterial activity. This study will help to enhance the knowledge of edible mushroom in production of novel bioactive compounds.

\section{Acknowledgements}

Authors are thankful to VIT University management, SIF, VIT University, Laboratory Assistants of School of Biosciences and Technology of VIT University, Vellore, India.

\section{References}

1. Sanmee R, Dell B, Lumyong P, Izumori K, Lumyong S. Nutritive value of popular wild edible mushrooms from northern Thailand. Food Chem. 2003;82:527-532. DOI: 10.1016/ S0308-8146(02)00595-2

2. Chang ST. Global impact of edible and medicinal mushrooms on human welfare in 21 st century: Nongreen revolution. Int J Med Mushrooms. 1999;1:1-7. DOI: 10.1615/IntJMed Mushrooms.v1. i1.10 
3. Aida FMNA, Shuhaimi M, Yazid M, Maaruf AG. Mushroom as a potential source of prebiotics: a review. Trends Food Sci Tech. 2009;20:567-575. DOI: 10. 1016/j.tifs.2009.07.007

4. Xu X, Yan H, Chen J, Zhang X. Bioactive proteins from mushrooms. Biotechnol Adv. 2011;29:667-674. DOI: 10.1016/j. biotechadv.2011.05.003

5. Mattilaa PA, Ronkainen R, Toivob J, Piironen V. Sterol and vitamin D2 contents in some wild and cultivated mushrooms. Food Chem. 2002;76:293-298. DOI: 10.1016/S0308-8146 (01)00275-8

6. Bao, X, Wang X, Dong Q, Fang J, Li X. Structural features of immunologically active polysaccharides from Ganoderma lucidum. Phytochemistry 2002;59:175-181. DOI: 10.1016/S00319422(01)00450-2

7. Zarenejad F, Yakhchali B, Rasooli I. Evaluation of indigenous potent mushroom growth promoting bacteria (MGPB) on Agaricus bisporus production. World J Microbiol Biotechnol. 2012;28:99-104. DOI: 10.1007/s11274-011-0796-1

8. Cho Y, Kim, J, Crowley DE, Cho B. Growth promotion of the edible fungus Pleurotus ostreatus by fluorescent pseudomonads. FEMS Microbiol Lett. 2003;218:271-276. DOI: 10.1016/ S0378-1097(02)01144-8

9. Young L, Chu J, Hameed A, Young C. Cultivable mushroom growth-promoting bacteria and their impact on Agaricus blazei productivity. Pesq agropec bras Brasília. 2013;48:636644. DOI: org/10.1590/S0100-204X2013000600009

10. El Enshasy HA, Hatti-Kaul R. Mushroom immunomodulators: unique molecules with unlimited applications. Trends Biotechnol. 2013;13:668-677. DOI: 10.1016/j.tibtech.2013.09.003

11. Vinodhkumar T, Maithili SS, Ramanathan G, Sudhakar .Antibacterial properties of secondary metabolites from endophytic marine algal bacterial population against chicken meat microbial pathogen. Int J Curr Sci. 2013;6:133-139.

12. Joseph B, Priya RM, Helen PAM, Sujatha S. Bio-active compounds in essential oil and its effects of antimicrobial, cytotoxic activity from the Psidiumguajava (L.) leaf. $J A d v$ Biotechnol. 2010;9:10-14.

13. Yuvaraj N, Kanmani P, Satishkumar R, Paari KA, Pattukumar $\mathrm{V}$, Arul V. Extraction, purification and partial characterization of Cladophor aglomerata against multidrug resistant human pathogen Acinetobacter baumannii and fish. World J Fish Mar Sci. 2011;3(1):51-57.

14. Buchholz A, Takors R, Wandrey C. Quantification of intracellular metabolites in Escherichia coli K12 using liquid chromatographic-electrospray ionization tandem mass spectrometric techniques. Anal Biochem. 2001;295:129-137. DOI: 10.1006/abio.2001.5183

15. Fox A. Carbohydrate profiling of bacteria by gas chromatography-mass spectrometry and their trace detection in complex matrices by gas chromatography-tandem mass spectrometry. J Chromatogr A. 1999;843:287-300. DOI: 10.1016/S00219673(98)00884-X

16. Saravanan V, Osborne J, Madhaiyan M, Mathew L, et al. Zinc metal solubilization by Gluconacetobacter diazotrophicus and induction of pleomorphic cells. J Microbiol Biotechnol. 2007;17(9):1477-1482.

17. Chen T, Chen Z, Ma GH, Du BH, Shen B, Ding YQ, Xu K. Diversity and potential application of endophytic bacteria in ginger. Genet Mol Res. 2014;13(3):4918-4931. DOI: 10.4238/ 2014.July.4

18. Mbai FN, Magiri EN, Matiru VN, Nganga J, Nyambati VCS. Isolation and characterisation of bacterial root endophytes with potential to enhance plant growth from kenyan basmati rice. Am Int J Contemp Res. 2013;3(4):25-40.

19. Guo B, Wang Y, SunX, Tang K. Bioactive natural products from endophytes: A review. Appl MicrobiolBiotechnol. 2008;44(2):136-142. DOI: 10.1134/S0003683808020026

20. Merkl R, Iveta H, Vladimir F, Jan S. Antimicrobial and antioxidant properties of phenolic acids alkyl esters. Czech J Food Sci. 2010;28(4):275-279.

21. Kokate CK, Regelson W. Review of the biology of Quercetin and related bioflavanoids. Food Chem Toxicol. 1995;33:10611080 . 